\title{
Helicobacter pylori: the gastric cancer problem
}

\author{
D Forman
}

Gastric cancer is the second most common fatal malignancy in the world and is the cause of more than 750000 deaths annually. ${ }^{1}$ In 1990, it was the fourteenth most frequent cause of death globally and, despite a general decline in the incidence, projections indicate that the annual number of new cases will increase significantly in the developing world during the next few decades as a result of adult population growth. ${ }^{1}$ Most gastric cancer is diagnosed at an advanced stage and survival is uniformly poor, usually no more than $15 \%$ at five years. ${ }^{2}$

There is now considerable evidence in support of an aetiological association between Helicobacter pylori infection and gastric cancer. ${ }^{3}$ Infection causes gastritis and the natural history of $H$ pylori associated gastritis over a period of decades is one of increasing degenerative changes and evolution towards atrophy, metaplasia and dysplasia. ${ }^{4}$ One prospective study has established that there is a significantly increased risk, in the order of ninefold, of developing precancerous gastric conditions when $H$ pylori positive patients were compared with those without infection. In addition, most of the descriptive epidemiology of gastric cancer parallels that for $H$ pylori infection, especially the strong association with poor socioeconomic conditions. ${ }^{6}$ Studies carried out within the Peoples Republic of $\mathrm{China}^{7}$ and internationally ${ }^{8}$ have shown a significant geographical correlation between gastric cancer mortality rates and the prevalence of $H$ pylori infection.

The most persuasive evidence indicative of an association is that from prospective serological studies of gastric cancer. ${ }^{9}$ These consistently show that there is roughly a threefold increased risk of cancer in $H$ pylori positive subjects and this can be translated into a worldwide burden of at least 300000 new cases of gastric cancer annually attributable to the infection. Very few established causes of cancer have been associated with an attributable risk of this magnitude. Understanding of the mechanistic basis of the $H$ pylori-cancer relation is also advancing rapidly and most evidence suggests that it is the chronic nature of the host inflammatory response and upregulation of various metabolites, such as reactive oxygen and nitric oxide, that are critical to the carcinogenic process. ${ }^{10}$ There is much that remains to be established about the relation, in particular the reasons why certain populations (notably in Africa) or patient groups (such as those with duodenal ulcers) have relatively low gastric cancer rates despite high levels of infection. The interaction between $H$ pylori infection and host factors in the development of gastric cancer also requires further investiga- tion. Such host factors may consist of genetic predisposition (for example, HLA haplotype ${ }^{11}$ ) or dietary differences (for example, vitamin C intake $^{12}$ ).

Researchers are also endeavouring to discover whether there are specific $H$ pylori strains associated with cancer. Most studies to date have looked at CagA status and several have reported a stronger risk of both gastric atrophy and intestinal-type gastric cancer in subjects infected with CagA positive strains of $H$ pylori. ${ }^{13-15}$ These data do not, however, show that subjects infected with CagA negative strains have no excess risk. In particular, they seem to be at an equivalent increased risk of diffuse-type gastric cancer as those with CagA positive infections. Thus, at the current time, no strains of $H$ pylori have been identified that are unambiguously cancer related.

A further important question is the extent to which $H$ pylori induced precancerous changes will regress or be prevented from progressing after eradication. There is very little peerreviewed literature on this subject and, although a number of preliminary reports have been published in abstract form, ${ }^{16-19}$ none of these studies are randomised and the results are remarkably inconsistent. The most optimistic data, from a Japanese study, ${ }^{20}$ indicate that patients with early gastric cancers which have been resected endoscopically show significantly less recurrence after $H$ pylori eradication. Without quantitative information addressing this question, it will be impossible to estimate the benefit in terms of cancer prevention that would occur from testing asymptomatic individuals for infection and treating those who are positive. It has, however, been shown in modelling studies that even with limited efficacy (preventing 30\% of gastric cancers in those treated), a test and treat strategy would be economically cost-effective. ${ }^{21}$ As the background cancer rate increases, so does the relative cost-effectiveness of such a strategy, although populations with the highest rates are frequently from developing countries where gastric cancer is one disease amongst many competing for limited health care resources and where high rates of adult reinfection may be a problem. Perhaps the optimal populations for employment of such a strategy, at least initially, are in countries such as Japan with high cancer rates and which are relatively affluent.

There are those who would advocate that a policy of screening for $H$ pylori within the general population and treating those found to be positive is now an appropriate strategy for gastric cancer prevention on the basis that it must be of some value and that there would be few adverse side effects. There are, however, several concerns about such a policy that can only be House, Cookridge

Leeds LS16 6QB, UK

D Forman 
tackled by further research. Apart from the critical question of quantifying how much cancer would be avoided, there are genuine concerns about the validity of giving millions of healthy people, tests and treatments that have largely been developed using thousands of unhealthy patients. The complex issue of induced antibiotic resistance is a major consideration as is the possibility of development of reflux disease ${ }^{22}$ and even development of oesophageal adenocarcinoma. ${ }^{23}$

Conclusive evidence which takes account of the risks and benefits of a screen and treat policy will only be derived from randomised controlled trials. These will have to be large and long term to judge the clinical or economic effectiveness of eradication. An important research priority, therefore, over the next decade will be to conduct such trials in order to produce the necessary evidence that could potentially prevent one of the world's major cancers.

1 Murray CJL, Lopez AD. Mortality by cause for eight regions of the world: Global Burden of Disease Study. Lancet 1997;349:1269-76.

2 Berrino F, Sant M, Verdecchia A, et al. Survival of cancer patients in europe: The Eurocare Study. IARC Scientific Publications No 132. Lyon: IARC, 1995

3 International Agency for Research on Cancer - World Health Organisation. Schistosomes, liver flukes and Helicobacter pylori. IARC Monographs on the evaluation of carcinobacter pylori. IARC Monographs on the evaluation of
genic risks to Humans No 61. Lyon: IARC, 1994.

genic risks to Humans No 61. Lyon: IARC, 1994 .
4 Correa P. Human gastric carcinogenesis: a multistep and multifactorial process - first American Cancer Society multifactorial process - first American Cancer Society award lecture on cancer epid
Cancer Res 1992;52:6735-40.

5 Kuipers EJ, Uyterlinde AM, Peña AS, et al. Long-term sequelae of Helicobacter pylori gastritis. Lancet 1995;345 1525-8.

6 Goodman KJ, Correa P. The transmission of Helicobacter pylori. A critical review of the evidence. Int $\mathcal{F}$ Epidemio 1995;24:875-87.

7 Forman D, Sitas F, Newell DG, et al. Geographic association of Helicobacter pylori antibody prevalence and gastric cancer mortality in rural China. Int $\mathcal{f}$ Cancer 1990; $46: 608-11$.

8 Eurogast Study Group. An international association beween Helicobacter pylori infection and gastric cancer. Lancet 1993;341:1359-62.

9 Forman D. The prevalence of Helicobacter pylori infection in gastric cancer. Aliment Pharmacol Ther 1995;9:71-6.

10 Goldstone AR, Quirke P, Dixon MF. Helicobacter pylori infection and gastric cancer. F Pathol 1996;179:129-37.

11 Beales ILP, Davey NJ, Pusey CD, et al. Long-term sequelae of Helicobacter pylori gastritis. Lancet 1995;346:381-2.

12 Goodman KJ, Correa P, Tengana Aux HJ, et al. Nutritional factors and Helicobacter pylori infection in Colombian children. $\mathcal{F}$ Pediatr Gastroenterol Nutr 1997;25:507-15.

13 Kuipers EJ, Pérez-Pérez GI, Meuwissen SGM, et al. Helicobacter pylori and atrophic gastritis: importance of the CagA status. F Natl Cancer Inst 1995;87:1777-80.

14 Blaser MJ, Pérez-Pérez GI, Kleanthous $\mathrm{H}$, et al. Infection with Helicobacter pylori strains possessing CagA is associated with an increased risk of developing adenocarcinoma of the stomach. Cancer Res 1995;55:2111-15.

15 Parsonnet J, Friedman GD, Orentreich N, et al. Risk for gastric cancer in people with CagA positive or CagA negative Helicobacter pylori infection. Gut 1997;40:297-301.

16 Cayla R, Carles B, de Mascarel A, et al. Long term follow up chronic gastritis after persistent Helicobacter pylori eradication in duodenal ulcer patients [abstract]. Gastroenterology 1995;108:A68

17 Van der Hulst RWM, Koycu B, Rauws EAJ, et al. The influence of cure of Helicobacter pylori infection on the ong-term sequelae of Helicobacter pylori gastritis [abstract]. Gastroenterology 1997;112:A320

18 Haruma K, Mihara M, Kamada T, et al. Eradication of Helicobacter pylori reverses intestinal metaplasia in patients with severe atrophic gastritis [abstract]. Gastroenterology 1997;112:A142

19 Griffiths AE, Thursz MR, Walker MM. Do intestinal metaplasia and gastric atrophy reverse after $\mathrm{H}$ pylori eradication [abstract]? Gut 1997;41(suppl 1):A48-9.

20 Uemura N, Mukai T, Okamoto S, et al. Effect of Helicobacter pylori eradication on subsequent development of cancer after endoscopic resection of early gastric cancer. Cancer Epidemiol Biol Prev 1997;6:639-42.

21 Parsonnet J, Harris RA, Hack HM, et al. Modelling cost-effectiveness of Helicobacter pylori screening to prevent gastric cancer: a mandate for clinical trials. Lancet 1996;348:150-4.

22 Labenz J, Blum AL, Bayerdörffer E, et al. Curing Helicobacter pylori infection in patients with duodenal ulcer may provoke reflux oesophagitis. Gastroenterology 1997;112:1442-7

23 Chow WH, Blaser MJ, Blot WJ, et al. An inverse relation between cagA ${ }^{+}$strains of Helicobacter pylori infection and risk of esophageal and gastric cardia adenocarcinoma. Cancer Res 1998;58:588-90. 